\title{
Psychological and psychopathological reactions in Honduras following Hurricane Mitch: implications for service planning
}

\author{
Robert Kohn, ${ }^{1}$ Itzhak Levav, ${ }^{2}$ Irma Donaire, ${ }^{3}$ Miguel Machuca, ${ }^{4}$ \\ and Rita Tamashiro 5
}

Suggested citiation

Kohn R, Levav I, Donaire I, Machuca M, Tamashiro R. Psychological and psychopathological reactions in Honduras following Hurricane Mitch: implications for service planning. Rev Panam Salud Publica. 2005;18(4/5):287-95.

\begin{abstract}
Background. Posttraumatic stress disorder (PTSD) and other psychopathological outcomes have not been sufficiently studied in community-based samples in Latin America. This study explored various psychopathological reactions and their respective risk factors two months after Hurricane Mitch struck Honduras in October 1998.

Methods. In the Honduran capital of Tegucigalpa, 800 respondents age 15 and older were selected from residential areas of high, middle, or low socioeconomic status that had suffered either high or low impact from the devastating effects of the hurricane. The Composite International Diagnostic Interview was used to diagnose PTSD. Depression, alcohol misuse, and grief reaction were examined using screening instruments, and the Self-Reporting Questionnaire was used to measure demoralization. The Impact of Event Scale was administered to ascertain the severity of the posttraumatic reaction.

Results. PTSD was present in $10.6 \%$ of the sample. Respondents from the high-impact residential areas were more distressed, had higher scores on the grief inventory, and showed greater severity in PTSD symptoms. The respondents from the high-impact residential areas also had higher prevalence rates of major depression, alcoholism, and prior emotional problems. The best explanatory model for the risk of developing PTSD included the degree of exposure based on reported traumatic events, and associated increased demoralization. Among the persons with PTSD, its severity was predicted by being female and by the degree of exposure to hurricane-related traumatic events.

Conclusions. Out of a total population of 3.3 million adults (age 15 and older) in Honduras, it is estimated that over 492000 of them may have developed PTSD due to Hurricane Mitch. Adequate health disaster preparedness and response requires full acknowledgement of the multiple psychological effects that victims experience.
\end{abstract}

Key words Disasters; mental health; mental disorders; stress disorders, post-traumatic; Honduras.

1 Brown University, Department of Psychiatry and Human Behavior, Providence, Rhode Island, United States of America. Send correspondence to: Robert Kohn, Butler Hospital, 345 Blackstone Blvd., Providence, Rhode Island 02906, United
States of America; telephone 401-455-6277; fax: 401-455-6566; e-mail: Robert_Kohn@brown.edu

2 Israel, Ministry of Health, Jerusalem, Israel.

3 Honduras, Ministry of Health, Tegucigalpa, Honduras.
4 Representation, Pan American Health Organization/ World Health Organization, Quito, Ecuador.

5 Universidad Nacional Autónoma, Department of Psychology, Tegucigalpa, Honduras. 
The scientific literature has repeatedly shown that natural and humanmade disasters leave in their wake short-, medium-, and long-term psychopathological reactions $(1,2)$. Posttraumatic stress disorder (PTSD) is the most commonly studied disorder in mental health disaster outcome research, although it is not the only psychopathological reaction. The role of culture in PTSD is complex, and so are the relationships that dose response, depression, demoralization, and substance use have with PTSD (3).

Most of the research on PTSD has been conducted in industrialized Western nations, with little research coming from developing regions, including Latin America. However, when natural disasters are measured by economic loss or the number of deaths and injuries, Asia is the most vulnerable region in the world, followed by Latin America. Of the 20 countries where the most deaths from disasters occurred between 1966 and 1990, 6 are located in Latin America (4).

To date, the mental health consequences of seven disasters in Latin America have been studied. In deriving a diagnosis of PTSD, most of these studies applied symptoms checklists rather than structured diagnostic instruments. In addition, the community was not the basis for the sampling framework. Investigations following the volcano eruption in Armero, Colombia, included persons from shelters and primary care clinics (5). Using a PTSD symptom checklist and clinical assessment, those researchers found a PTSD rate of $32 \%$ in the shelters and of $42 \%$ in the clinics. One published study on the effects of Hurricane Mitch on Nicaragua included an investigation of adolescents from three public schools who had had different degrees of exposure to the impact of the hurricane on their community (6). Assessment for PTSD was made using the Child Posttraumatic Stress Disorder Index. A second study in Nicaragua, which targeted adults, was based on consecutive patients in four primary health care centers (7). PTSD symptoms were measured using the Harvard Trauma Questionnaire. This study found a prevalence rate of
$4.5 \%$ in the least-damaged area and of $9.0 \%$ in the most-damaged area (7).

A study examining the effects of Hurricane Paulina in Mexico utilized the Revised Civilian Mississippi Scale in the community; however, a quota rather than a random sample was employed (8). De la Fuente (9) conducted two studies on the impact that victims living in shelters had suffered from an earthquake in Mexico. These studies used a questionnaire probing psychiatric symptoms based on the Diagnostic and Statistical Manual, third edition (DSMIII), and found rates of PTSD of $32 \%$.

To date, only three studies following natural disasters in Latin America have used structured diagnostic interview schedules to make a diagnosis of PTSD. The Diagnostic Interview Schedule (DIS) and Structured Clinical Interview for DSM-III were used to make a diagnosis of PTSD among 524 individuals following an earthquake in Mexico. A rate of $32 \%$ was found; women had higher rates than did men (10). In Puerto Rico the DIS was readministered to 521 persons previously interviewed in a representative national sample after a flood. The group who had been exposed to the flood had a rate of PTSD of $3.7 \%$, and the unexposed group had a rate of $0.7 \%(11,12)$.

Several studies have suggested that Hispanic populations may be more vulnerable to PTSD. Using the DIS, Durkin examined the rate of PTSD among victims of earthquakes in the country of Chile and in the state of California in the United States (13); the rate in Chile was $19 \%$, versus $3 \%$ in California. The Chilean sample was based on residents of a housing complex, while the California sample was based on a household survey. In a study of Hurricane Andrew in the United States, Spanish-speaking Latinos had higher rates of PTSD symptoms than did either Hispanics who choose to be interviewed in English or non-Hispanics (14).

Despite the relative scarcity of current research on Latin America, the available data suggest that disasters lead to considerable mental health morbidity. However, health officials and decisionmakers often overlook the mental health impact of disasters. This occurs, for example, because the authorities are overwhelmed by the immediate human and material losses, environmental consequences, destruction of health centers, and risk of epidemics. In addition, the mental health impact of disasters may be ignored due to the stigma of psychiatric disorders.

The objective of this communitybased study was to investigate the risk of PTSD and other psychopathological reactions, including demoralization, depression, grief, and alcohol misuse, several months after Honduras was struck by Hurricane Mitch in 1998. The study was done in Tegucigalpa, the capital city of the country. Several measures of dose response were employed, and, unlike other studies, the sampling design was developed to specifically study the role of socioeconomic status as a risk factor for developing psychopathology.

\section{METHODS}

\section{The setting}

Hurricane Mitch hit Central America on 25 October 1998 with wind speeds up to $285 \mathrm{~km} / \mathrm{hr}(150 \mathrm{mi} / \mathrm{hr})$. This was the most devastating disaster to affect Central America in a century.

Honduras suffered the brunt of the disaster. The Pan American Health Organization (PAHO) and the Honduran Government estimated that 1.5 million of Honduras' population of 6.4 million were displaced by the hurricane, 5657 were killed, and 8058 more were never found. Another 112272 persons were reported injured. Approximately 1375 shelters had to be established to accommodate 285000 persons who were evacuated (15). In the region where Tegucigalpa is located, 404225 individuals were displaced; of those, 22429 were housed in 165 shelters (16). Fifteen of the 29 hospitals in the country were rendered inoperable by the hurricane. Thirty percent of the country's health infrastructure was damaged. Eighty percent of the population had difficulty accessing drinking water. Marked increases in intestinal diseases, cholera, malaria, and dengue were seen. 


\section{Sample selection}

The study was conducted in December 1998 and January 1999. A sample of 800 adults (age 15 and older) stratified by the socioeconomic status (SES) of the neighborhood was selected. One-half of the adults were from lowSES neighborhoods, one-fourth from middle-SES neighborhoods, and onefourth from high-SES neighborhoods. The SES groups were stratified by high-impact and low-impact neighborhoods. The selection and determination of which neighborhoods were considered to be high and low impact was done in consultation with the Secretariat of Health in Honduras. A neighborhood was considered to have suffered high impact if nearly all the homes were destroyed. Individuals in the low-SES highly impacted strata were further subdivided into two groups: those remaining in the community (either still residing in their original homes or having moved elsewhere in the community) and those temporarily housed in shelters.

For the persons remaining in the community, the housing units were selected from predetermined neighborhoods based on SES and impact. The number of homes in each neighborhood was counted regardless of whether the house was intact or not. The first house selected was at the beginning of each street. The subsequent house selected was based on the number of homes in the area divided by the number of interviews needed for the respective strata. Homes were selected regardless of whether or not they were destroyed or occupied. If a house was unoccupied or destroyed, the residents of the home prior to it were located if they resided in Tegucigalpa by asking neighbors and reconstruction workers. If the residents of the designated house could not be located, the subsequent house was selected. Consecutive households were selected in the districts where houses were destroyed and in the poor neighborhoods where it was extremely difficult to ascertain the individual unit, such as with a slum dwelling where one family unit was built next to or on top of another. For individuals living in the sampled shelters, all families were included.

In a brief interview the initial household resident who was contacted provided a description of the exposure of the hurricane on the home and the family. This informant provided a list of all the individuals, including the informant, who resided in the home at the time of the hurricane, in order for us to select for a more-extensive interview one target respondent per household, according to the Kish procedure (17). Those age 15 and older were eligible.

The Secretary of Health of Honduras and the Representation of the Pan American Health Organization in Honduras approved both the interview schedule and the consent forms for human rights safeguard. Written informed consent was obtained from the person providing the information about the residents of the home and also from the subject who underwent the more-extensive interview. Each of the interviewers was provided a letter of introduction from the Secretary of Health identifying them as an interviewer for this study.

\section{Interview schedule}

The interview of the target respondent included sections on demographic information, demoralization, depression, posttraumatic stress, alcohol abuse, help-seeking, and exposure to trauma. A psychiatrist and a Honduran psychologist translated the scales that did not have an available Spanish version. All items were evaluated for cultural validity by the team and modified for the local usage, and to fit the events related to the hurricane.

Demoralization was measured using the Self-Reporting Questionnaire (SRQ) (18). Since the objective of the study was to determine current psychiatric and psychological problems, the SRQ was modified to inquire about the last seven days rather than the past month. The SRQ had been validated in neighboring Nicaragua, with a cutoff of nine positive symptom items being found to be appropriate as a screen for probable psychiatric cases in the general community (19). The SRQ schedule also included five items on alcohol abuse, which were modified to tap into behaviors that occurred since the hurricane. This scale had been used globally, including in Latin America (20). To measure losses resulting from the hurricane, five items from the Texas Inventory of Grief were used (21). The Texas Inventory of Grief was administered in only half of the interviews.

To evaluate for the presence of current major depression a DSM-IV / International Classification of Diseases Tenth Revision symptom checklist inquiring into the presence of diagnostic symptoms in the past two weeks was used. This instrument had been previously used in a multicenter study of primary care practices throughout Latin America (22). DSM-IV diagnosis of PTSD was obtained using the Spanish-language version 2.1 of the Composite International Diagnostic Interview Schedule (CIDI) PTSD module, a diagnostic interview schedule (23). The module obtained the current diagnosis, and each question was modified so that it only referred to the hurricane and to no other traumatic event. Presence of current PTSD symptoms and their severity in the past seven days was further evaluated by using the Impact of Event Scale (IES) (24). The total score on the IES is derived by the sum of positive responses. The IES consists of two subscales, one for intrusion and one for avoidance. Again, the items were linked directly to the hurricane rather than being left open to other traumatic events.

A single item was included in the interview schedule to control for the presence of any predisaster psychological problem: "Did you have problems with your nerves before the hurricane?" This was followed by questions evaluating the degree of traumatic exposure that occurred during the hurricane (see Table 2 for a list of items). Positive responses to these items were summed to form an exposure index (Chronbach's alpha $=0.58)$.

The interview also asked about exposure to violence following the hurricane (witnessing violence, being as- 
saulted, someone assaulting your child, or assaulting someone). The interview concluded with a series of items about the utilization of any medical or mental health assistance after the disaster, and the resources that might be used in the future.

\section{Analysis}

Risk factors for psychopathology were examined using both univariate and multivariate analyses. Chi-square tests and $t$ tests were used in the univariate analysis. Logistic regression was used to determine the odds ratios (ORs) and the 95\% confidence intervals (CIs) for potential risk of PTSD. Multivariate regression analysis was used to examine predictors of severity of PTSD. Backwards regression analyses were utilized to determine the best-fitting models. Low SES, middle SES, and high SES plus high-impact or low-impact neighborhood were included in each of the regression models since they were basic stratification variables in the sample design. Statistical tests were considered to be significant at the $P<0.05$ level. The statistical analysis was conducted using the SUDAAN software program to adjust the standard errors (SEs) for the stratified sample design (25).

\section{RESULTS}

\section{Exposure and psychopathology}

Eight hundred interviews were completed, stratified as follows: low impact and high SES, 100; low impact and middle SES, 101; low impact and low SES, 199; high impact and high SES, 100; high impact and middle SES, 100; high impact and low SES not in a shelter, 98; and high impact and low SES in a shelter, 102. Females constituted $61.4 \%$ of the sample. The average age of the subjects was 37.0 years (standard deviation, 16.8 years). Residence in a high-impact or low-impact neighborhood was not significantly associated with any of the demographic variables other than having to un- dergo a change in occupation following the hurricane. The demographic characteristics of the sample are shown in Table 1.

Table 2 reports the proportion of persons who experienced any of six traumatic events whose occurrence during the hurricane we asked about, for all the respondents, the low-impact stratum, and the high-impact stratum. The six events were: the house was damaged, witnessed someone being injured, witnessed someone die, was injured, lost one's belongings, and lost a pet. Each event was reported at a statistically higher rate in the high-impact group. Twelve individuals, including two from the low-impact group, reported witnessing someone die. The high-impact group had a significantly increased

TABLE 1. Demographic characteristics (\%) of the sample in study of psychological and psychopathological reactions in Honduras following Hurricane Mitch, for all respondents, those in low-impact neighborhoods, and those in high-impact neighborhoods

\begin{tabular}{|c|c|c|c|c|c|}
\hline Variable & $\begin{array}{c}\text { Total } \\
\text { sample } \\
(n=800)\end{array}$ & $\begin{array}{l}\text { Low-impact } \\
\text { neighborhoods } \\
(n=400)\end{array}$ & $\begin{array}{c}\text { High-impact } \\
\text { neighborhoods } \\
(n=400)\end{array}$ & Chi-square/(df) ${ }^{a}$ & $P$ \\
\hline Gender & & & & $1.36(1)$ & 0.24 \\
\hline Female & 61.4 & 63.4 & 59.4 & & \\
\hline Male & 38.6 & 36.6 & 40.6 & & \\
\hline Marital status & & & & $8.92(5)$ & 0.11 \\
\hline Married & 29.3 & 29.8 & 30.1 & & \\
\hline Common-law & 21.7 & 20.7 & 22.7 & & \\
\hline Never married & 38.0 & 41.2 & 34.9 & & \\
\hline Widowed & 4.0 & 4.1 & 3.9 & & \\
\hline Divorced/Separated & 7.0 & 4.2 & 8.4 & & \\
\hline Education completed & & & & $1.06(3)$ & 0.79 \\
\hline No school & 6.7 & 6.3 & 7.0 & & \\
\hline Primary school & 36.1 & 34.9 & 37.3 & & \\
\hline Secondary school & 34.9 & 35.8 & 34.1 & & \\
\hline University & 22.3 & 23.0 & 21.6 & & \\
\hline Current occupation & & & & $5.51(4)$ & 0.24 \\
\hline Employed & 53.1 & 52.4 & 53.8 & & \\
\hline Unemployed & 22.3 & 20.9 & 23.7 & & \\
\hline Housewife & 17.2 & 18.4 & 15.9 & & \\
\hline Student & 5.1 & 6.6 & 3.7 & & \\
\hline Retired & 2.3 & 1.7 & 2.9 & & \\
\hline Occupation prior to hurricane & & & & $16.72(2)$ & 0.0003 \\
\hline Same employment & 59.2 & 63.4 & 54.9 & & \\
\hline Other employment & 17.3 & 11.8 & 22.9 & & \\
\hline Unemployed & 23.5 & 24.7 & 22.2 & & \\
\hline
\end{tabular}

a The degrees of freedom (df) are in parentheses.

TABLE 2. Proportion (\%) of persons who reported exposure to traumatic events during the hurricane, in study of psychological and psychopathological reactions in Honduras following Hurricane Mitch

\begin{tabular}{lcccrr}
\hline \multicolumn{1}{c}{ Event } & $\begin{array}{c}\text { Total } \\
\text { sample } \\
(n=800)\end{array}$ & $\begin{array}{c}\text { Low-impact } \\
\text { neighborhoods } \\
(n=400)\end{array}$ & $\begin{array}{c}\text { High-impact } \\
\text { neighborhoods } \\
(n=400)\end{array}$ & Chi-square $^{\mathrm{a}}$ & $P$ \\
\hline House was damaged & 29.5 & 19.7 & 39.4 & 44.49 & 0.0001 \\
Saw someone injured & 4.9 & 1.6 & 8.2 & 16.19 & 0.0001 \\
Saw someone die & 1.6 & 0.6 & 2.7 & 4.83 & 0.03 \\
Respondent was injured & 5.1 & 1.6 & 8.6 & 19.06 & 0.0001 \\
Lost belongings & 26.6 & 4.8 & 48.5 & 281.63 & 0.0001 \\
Lost pet & 8.9 & 2.0 & 15.9 & 47.79 & 0.0001 \\
\hline
\end{tabular}

a Degrees of freedom $=1$ for the chi-square test. 
exposure index $(t=-13.79$, degrees of freedom $(\mathrm{df})=793, n=793, P<0.0001)$ in contrast to the low-impact group.

Exposure to violence following the hurricane, reported by over one-third of the population, did not differ significantly by impact group.

PTSD, as diagnosed by the CIDI, was present in $10.6 \%$ ( $\mathrm{SE}=1.1 \%$ ) of the sample two months following the hurricane. Table 3 shows the prevalence rates by high-impact and low-impact neighborhood, and Table 4 presents the rates by the three levels of SES. Each of the three disorders was significantly higher among those in the highimpact group, and that was also true for those in the low-SES group. The relationship between SES and the three diagnoses was not a result of higher exposure to the traumatic events in the low-SES group, given that the interaction between SES and the exposure index was not statistically significant. The proxy one-item measure of predisaster psychopathology, "prior nerves," was also more prevalent among those in the high-exposure group (23.5\%) than in the low-exposure group (16.6\%) (chi-square $=5.86, \mathrm{df}=1, P<0.02$ ). The prevalence of "prior nerves" was inversely related to SES (chi-square = 16.26, $\mathrm{df}=2, P<0.0003$ ).

There were significant differences between the two impact groups in the degree of demoralization as measured by the SRQ. Respondents in the highimpact group were more distressed $(t=-4.45, \mathrm{df}=793, n=772, P<0.0001)$ and had higher scores in the Texas Inventory of Grief $(t=-4.88, \mathrm{df}=793$, $n=394, P<0.0001)$. The IES also was elevated in the high-impact group, including the intrusion subscale $(t=$ $-4.55, \mathrm{df}=793, n=783, P<0.0001)$, the avoidance subscale $(t=-4.10, \mathrm{df}=793$, $n=786, P<0.0001$ ), and the total score $(t=-4.74, \mathrm{df}=793, n=773, P<0.0001)$.

About one-fourth of the total sample sought medical consultation in the two months following the hurricane, but the $28.9 \%$ proportion among the highimpact group and the $24.2 \%$ among the low-impact group were not significantly different. Nor were there statistical differences with regard to those who sought assistance for emotional

TABLE 3. Prevalence rates (\%) of psychiatric disorders by impact group, in study of psychological and psychopathological reactions in Honduras following Hurricane Mitch

\begin{tabular}{lcccrr}
\hline \multicolumn{1}{c}{ Disorder } & $\begin{array}{c}\text { Total } \\
\text { sample } \\
(n=800)\end{array}$ & $\begin{array}{c}\text { Low-impact } \\
\text { neighborhoods } \\
(n=400)\end{array}$ & $\begin{array}{c}\text { High-impact } \\
\text { neighborhoods } \\
(n=400)\end{array}$ & Chi-square $^{\mathrm{a}}$ & $P$ \\
\hline PTSD $^{\text {b }}$ & 10.6 & 7.9 & 13.4 & 6.02 & 0.02 \\
Major depression & 19.5 & 14.9 & 24.4 & 10.56 & 0.002 \\
Alcoholism & 5.8 & 3.7 & 8.0 & 6.03 & 0.02 \\
\hline
\end{tabular}

a Degrees of freedom $=1$ for the chi-square test.

${ }^{b}$ PTSD $=$ posttraumatic stress disorder .

TABLE 4. Prevalence rates (\%) of psychiatric disorders by socioeconomic status (SES), in study of psychological and psychopathological reactions in Honduras following Hurricane Mitch

\begin{tabular}{|c|c|c|c|c|c|}
\hline Disorder & $\begin{array}{c}\text { Low } \\
\text { SES } \\
(n=399)\end{array}$ & $\begin{array}{c}\text { Middle } \\
\text { SES } \\
(n=201)\end{array}$ & $\begin{array}{c}\text { High } \\
\text { SES } \\
(n=200)\end{array}$ & Chi-square $^{a}$ & $P$ \\
\hline PTSD $^{b}$ & 15.7 & 3.7 & 7.7 & 26.66 & 0.0001 \\
\hline Major depression & 25.9 & 11.0 & 15.6 & 22.79 & 0.0001 \\
\hline Alcoholism & 8.0 & 4.6 & 2.8 & 7.64 & 0.03 \\
\hline
\end{tabular}

a Degrees of freedom $=2$ for the chi-square test.

${ }^{b}$ PTSD = posttraumatic stress disorder.

problems, with that being $10.3 \%$ among the high-impact group and $7.4 \%$ among the low-impact group.

\section{Risk factors for posttraumatic stress disorder}

Each logistic regression analysis that examined risk factors for CIDI-PTSD included impact group and SES since these characteristics were used to stratify the sample. Females were at a markedly increased risk $(\mathrm{OR}=2.1$, 95\% CI: 1.2-3.4). Increasing age appeared to have a small but statistically significant increased risk for PTSD $(\mathrm{OR}=1.02$; 95\% CI: 1.00-1.03). Living in a common-law relationship (in contrast to being married) had an increased risk for PTSD $(\mathrm{OR}=2.1 ; 95 \%$ CI: 1.1-4.1). Level of education and being unemployed (prior to or since the hurricane) were not significantly associated with increased risk for PTSD. When gender, age, and marital status were all included in the model along with impact group and SES, each of these three variables remained statistically significant.

Exposure to the traumatic events due to the hurricane that were risk factors for PTSD included: house being damaged $(\mathrm{OR}=3.4 ; 95 \% \mathrm{CI}: 2.0-5.7)$; seeing someone injured ( $\mathrm{OR}=2.9 ; 95 \%$ CI: 1.1-7.4); losing one's belongings $(\mathrm{OR}=3.0 ; 95 \%$ CI: 1.5-5.9); and loss of a pet $(\mathrm{OR}=3.6$; 95\% CI: 1.9-7.0). Being injured during the hurricane did not reach statistical significance $(\mathrm{OR}=2.2$; 95\% CI: 0.9-5.1). The exposure index was predictive of PTSD (OR $=1.9 ; 95 \%$ CI: 1.5-2.5).

As for violent events following the hurricane, witnessing violence $(\mathrm{OR}=$ 3.4; 95\% CI 1.8-6.4) increased the risk of developing PTSD related to the hurricane. However, having been assaulted $(\mathrm{OR}=2.2$; 95\% CI: 0.8-5.9) or having a child who was assaulted $(\mathrm{OR}=1.2 ; 95 \%$ CI: 0.9-1.7) were not associated with PTSD due to the hurricane.

Comorbid psychopathological reactions and conditions were in part asso- 
ciated with increased risk for the diagnosis of PTSD following the hurricane. Major depression $(\mathrm{OR}=11.1 ; 95 \% \mathrm{CI}$ : 6.5-18.9) and predisaster problems with nerves (OR $=1.4 ; 95 \%$ CI: $1.3-1.6)$ were associated risk factors, but not alcoholism (OR = 1.9; 95\% CI: 0.8-4.3). Alcoholism was associated with increased risk for PTSD, controlling for gender $(\mathrm{OR}=3.4 ; 95 \% \mathrm{CI}: 2.4-8.2)$. Demoralization was also comorbid with PTSD, based on the SRQ (OR = 1.3; 95\% CI: 1.3-1.4). The Texas Inventory of Grief scale was not associated with PTSD. A logistic regression model that included only the possible comorbid conditions, demoralization, major depression, and "prior nerves," along with the stratification variables, was created. This model resulted in demoralization $(\mathrm{OR}=1.3 ; 95 \% \mathrm{CI}: 1.2-1.4)$ and major depression $(\mathrm{OR}=2.1 ; 95 \%$ CI: 1.0-4.5) remaining significant $\mathrm{CO}^{-}$ variates, but not "prior nerves."

A backward logistic regression analysis was conducted using impact group, SES, gender, marital status, age, demoralization based on the SRQ, major depression, alcoholism, "prior nerves," and exposure index to determine the best-fitting model of the studied risk factors for PTSD. Only demoralization $(\mathrm{OR}=1.3 ; 95 \% \mathrm{CI}: 1.2-1.4)$ and the exposure index $(\mathrm{OR}=1.6 ; 95 \%$ CI: 1.2-2.1) remained statistically significant. Gender, age, "prior nerves," major depression, and alcoholism did not remain in the model; neither SES nor impact group remained statistically significant.

Individuals with CIDI-PTSD were much more likely to use health services following the hurricane compared to those without PTSD (48.5\% versus $23.5 \%$; OR $=2.8 ; 95 \% \mathrm{CI}: 1.7-4.5)$, as well as to consult for psychological issues $(30.1 \%$ versus $6.1 \%$; OR $=5.7 ; 95 \%$ CI: 3.1-10.3).

\section{Severity of posttraumatic stress disorder}

An increased score on the IES was moderately associated with increased CIDI-PTSD risk for the total score $(\mathrm{OR}=1.1 ; 95 \% \mathrm{CI}: 1.1-1.1)$, the avoid- ance subscale $(\mathrm{OR}=1.1 ; 95 \% \mathrm{CI}$ : 1.1-1.1), and the intrusion subscale $(\mathrm{OR}=1.2 ; 95 \% \mathrm{CI}: 1.1-1.2)$. Severity was examined using the IES total score among those who had PTSD, using multiple regression models. The stratification variables, impact group, and SES were not related to severity of PTSD. Females with PTSD had higher scores than did men on the IES ( $\beta=$ 8.37, $\mathrm{SE}=4.23, P<0.05)$. Age, marital status, and unemployment prior to or after the hurricane were not related to PTSD severity. Seeing someone being injured $(\beta=10.59, \mathrm{SE}=4.21, P<0.02)$, getting injured during the hurricane $(\beta=11.31, \mathrm{SE}=3.95, P<0.0002)$, and losing one's belongings $(\beta=10.43$, $\mathrm{SE}=3.20, P<0.002)$ were events significantly associated with increased severity of the disorder. The exposure index also predicted more severe PTSD $(\beta=4.47$, SE $=1.17, P<0.0001)$. Exposure to post-hurricane violence was not related with severity of PTSD. Major depression, alcoholism, and prior problems with nerves did not correlate with severity. Increased demoralization $(\beta=0.99$, SE $=0.33, P<$ $0.004)$ was significantly associated with more severe PTSD, but not for the measure for grief. Seeking medical or mental health services was not associated with severity of PTSD.

A backward regression analysis was conducted to determine which factors were predictive of severity of PTSD. Gender, demoralization, exposure index, and the two stratification variables were included in the initial model. The significant variables in the final model included being female $(\beta=9.56, \mathrm{SE}=$ $3.54, P<0.008)$ and the exposure index $(\beta=4.66, \mathrm{SE}=1.13, P<0.0001)$.

\section{DISCUSSION}

PTSD appeared in $10.6 \%$ of the respondents. This rate of PTSD was much lower than in most Latin American studies examining disasters. This finding may be explained by the utilization of a diagnostic instrument that was clearly linked to the event, and to the community-based sampling design that we used. As noted, previous studies used symptoms checklists rather than diagnostic tools and relied on selected populations.

Latin American studies on PTSD have also led to mixed results concerning whether a dose response is related to an increased risk of developing PTSD. A study of Guatemalan refugees living in Mexico found no association between the number of warrelated trauma events reported and symptoms of PTSD (26). In contrast, Caldera et al. (7), who conducted a research study on the effects that Hurricane Mitch had in the neighboring country of Nicaragua, suggested that there was a dose response that depended on the degree of impact on the different communities from which the samples were drawn. Two measures of impact/exposure were employed in our study of Honduras: (1) impact on neighborhood, an ecological measure, and (2) an exposure index, which reflected the individual's own experience based on the number of trauma events. Although both were associated with an increased risk for PTSD, in the final model only the individual's own exposure experience remained significant. Importantly, the severity of PTSD was associated only with individual exposure factors.

Major depression, demoralization, prior emotional disorder, and alcoholism in men were all associated with PTSD. However, following control for other covariates, only demoralization remained significant in the analysis. Curiously, comorbidity was not predictive of severity of PTSD. Our measure of major depression and alcoholism was based on symptom scales and not on a diagnostic instrument, unlike the procedure that we followed to ascertain PTSD. This is a limitation of this study, and conceivably the relationship with comorbidity might have been different. Furthermore, our study could not differentiate incident cases of major depression and alcoholism following the hurricane from those with a preexisting condition. We did use a proxy measure for prior psychopathology, although its validity is open to interpretation.

Prior research has suggested that socioeconomic status is a risk factor for 
disaster-related PTSD (2), yet SES has been less often investigated than other issues such as dose response or comorbidity. Disasters have the potential to affect people differentially. Disasters may have a higher impact the lower the social class of the victim is. That is because poorer people have fewer resources before a disaster, and are thus more likely to exhaust their assets before the disaster situation ends. Furthermore, the risk of being affected by a disaster is not equal across SES groups; the lower the socioeconomic level of a neighborhood, the higher the impact. Our Honduras study found mixed results for the role of SES. Those in the low-SES group have markedly higher rates of PTSD, suggesting an increased risk. Increased risk of exposure itself did not explain the inverse relationship between PTSD and SES, suggesting that lower SES itself increases the risk for PTSD. SES, however, is not a strong predictor for PTSD and was not significant in the final model. In addition, SES did not predict severity of PTSD.

The magnitude of the mental health reactions associated with Hurricane Mitch was considerable. Based on the census of Honduras, which indicated a total population of 3.3 million age 15 and older in 1998, we estimated that over 492000 adults may have developed PTSD from Hurricane Mitch alone. We also noted in our study the post-disaster violence that may have been a result of community disorganization and deprivation. Our findings do not reflect post-disaster PTSD from secondary trauma.

In our study a sizable proportion $(30 \%)$ of those individuals with PTSD attempted to get assistance for their psychiatric problems. Unfortunately, this study did not ascertain the type or quality of the assistance provided. Although not all those affected may require direct intervention, some largescale interventions may be needed. Such an intervention might reduce the risk of secondary reactions by turning non-understandable symptoms into understandable ones and by suggesting ways of coping with psychiatric symptoms, including seeking help from mental health services.
FIGURE 1. The nature of the disaster and its impact on the individual
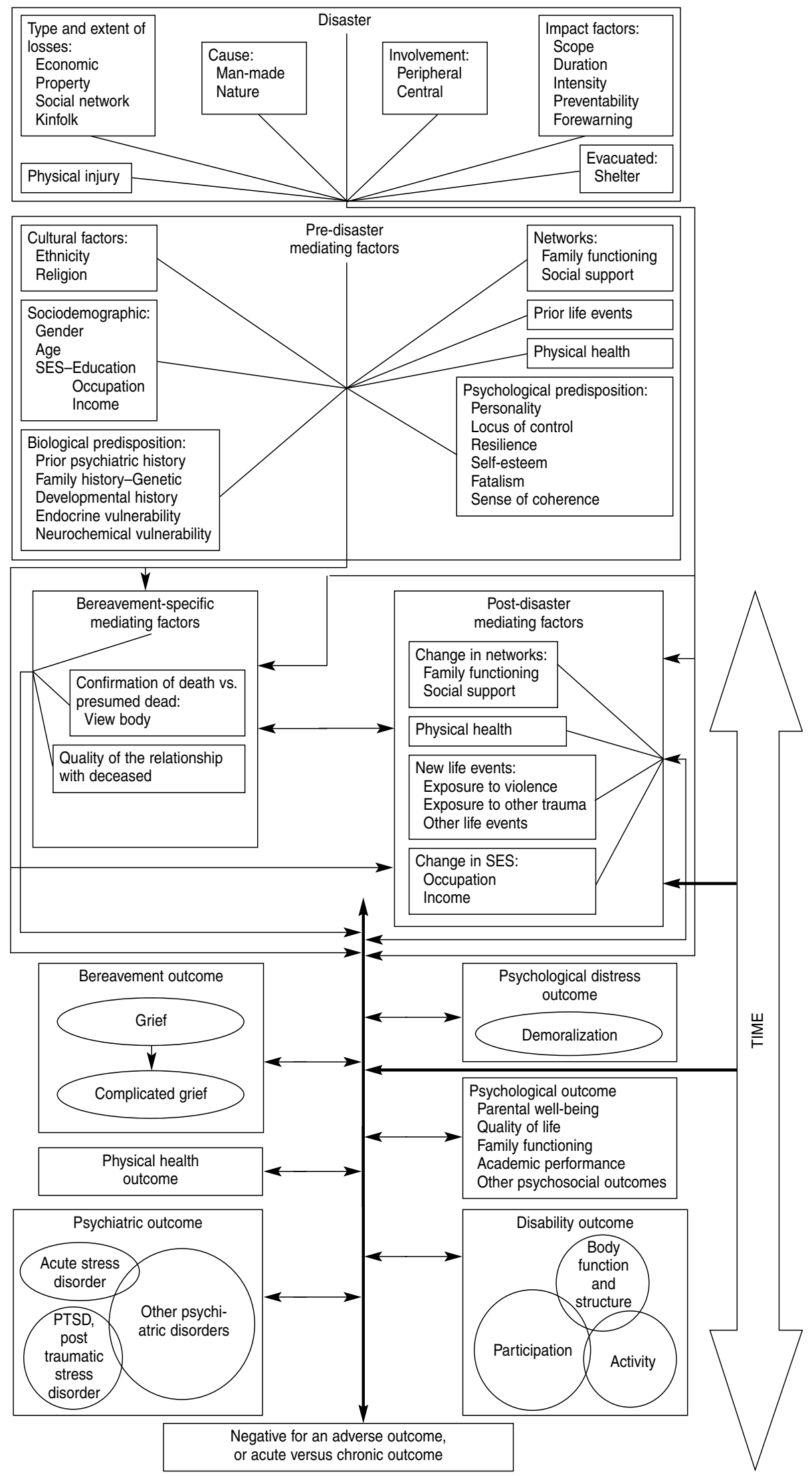
Mental health disaster response requires an understanding of the nature of the disaster and its impact on the individual (Figure 1). This includes the type and extent of the loss, the cause of the disaster, the involvement of the individual (central versus peripheral), impact of the disaster, whether the person was evacuated, and if physical injury occurred. Taken together, these factors constitute the individual's disaster experience. Three broad types of mediating factors should be accounted for in addressing an individual's needs following a disaster (27): those that preceded the disaster, those that arose after the disaster, and those that are related to situations involving bereavement. From the public health perspective, each of these mediating factors needs to be taken into account. For example, our study suggested that personal losses, in particular property losses, have a great impact on acute psychopathology. This might suggest that public health action focused on restoring housing and other essential goods and in supporting the process of financial recovery might alone result in a positive mental health outcome for many. Mental health services need to be designed to address the complexity of the disaster experience, and the services need to include surveillance of the affected population over time.

Little research is available on the long-term outcome of disasters, particularly for low-income populations. Men- tal health outcomes are diverse, and they may include bereavement, demoralization, psychosocial concerns (such as parental well-being, quality of life, family functioning, and academic performance), physical health problems, psychiatric disorders, and disability-as well as no adverse outcome. Mental health planning should not cease with just the conclusion of the acute event; health care providers must be prepared to treat those who remain in protracted vulnerability and have long-term chronic conditions as a result of trauma.

Acknowledgments. We thank our interviewers for their dedication and Beth Hott for her assistance with the data management and the manuscript.

\section{REFERENCES}

1. Logue JN, Melick ME, Hansen H. Research issues and directions in the epidemiology of health effects of disasters. Epidemiol Rev. 1981;3:140-62.

2. Norris FH, Friedman MJ, Watson PJ, Byrne CM, Diaz E, Kaniasty K. 60,000 disaster victims speak: part I. An empirical review of the empirical literature, 1981-2001. Psychiatry. 2002;65:207-39.

3. Kroll J. Posttraumatic symptoms and the complexity of responses to trauma. JAMA. 2003;290:667-70.

4. Noji EK. The nature of disasters: general characteristics and public health effects. In: Noji $\mathrm{EK}$, ed. The public health consequences of disasters. New York: Oxford University Press; 1997. Pp. 3-20.

5. Lima BR, Pai S, Santacruz H, Lozano J. Psychiatric disorders among poor victims following a major disaster: Armero, Colombia. J Nerv Ment Dis. 1991;179:420-7.

6. Goenjian AK, Molina L, Steinberg AM, Fairbanks LA, Alvarez ML, Goenjian HA, et al. Posttraumatic stress and depressive reactions among Nicaraguan adolescents after hurricane Mitch. Am J Psychiatry. 2001;158:788-94.

7. Caldera T, Palma L, Penayo U, Kullgren G. Psychological impact of the hurricane Mitch in Nicaragua in a one-year perspective. Soc Psychiatry Psychiatr Epidemiol. 2001;36: 108-14.

8. Norris FH, Perilla JL, Murphy AD. Postdisaster stress in the United States and Mexico: a cross-cultural test of the multicriterion conceptual model of posttraumatic stress disorder. J Abnorm Psychol. 2001;110:553-63.

9. De la Fuente R. The mental health consequences of the 1985 earthquakes in Mexico. Int J Ment Health. 1990;19:21-9.
10. Tapia Conyer R, Sepúlveda Amor J, Medina Mora ME, Caraveo J, de la Fuente JR. Prevalencia del síndrome de estrés postraumático en la población sobreviviente de un desastre natural. Salud Publica Mex. 1987;29:406-11.

11. Bravo M, Rubio-Stipec M, Canino GJ, Woodbury MA, Ribera JC. The psychological sequelae of disaster stress prospectively and retrospectively evaluated. Am J Community Psychol. 1990;18:661-80.

12. Canino GC, Bravo M, Rubio-Stipec M, Woodbury $M$. The impact of disaster on mental health: prospective and retrospective analyses. Int J Ment Health. 1990;19:51-69.

13. Durkin ME. Major depression and posttraumatic stress disorder following the Coalinga and Chile earthquakes: a cross-cultural comparison. J Soc Behav Pers. 1993;8:405-20.

14. Perilla JL, Norris F, Lavizzo EA. Ethnicity, culture, and disaster response: identifying and explaining ethnic differences in PTSD six months after Hurricane Andrew. J Soc Clin Psychol. 2002;21:20-45.

15. Honduras, Secretaría de Salud. Huracán Mitch en Honduras 1998. Tegucigalpa: Secretaría de Salud; 1999.

16. Honduras, Secretaría Técnica y de Cooperación Internacional. Número de personas damnificadas y en albergues. Tegucigalpa: SETCO; 1998

17. Kish L. Survey sampling. New York: John Wiley \& Sons; 1965.

18. Beusenberg M, Orley J. A user's guide to the Self Reporting Questionnaire. Geneva: World Health Organization, Division of Mental Health; 1994.

19. Penayo U, Kullgren G, Caldera T. Mental disorders among primary health care patients in Nicaragua. Acta Psychiatr Scand. 1990;82: $82-5$.

20. Climent CE, Arango MV. Manual de psiquiatría para trabajadores de atención primaria. Washington, D.C.: Organización Panamericana de la Salud; 1983. (Serie PALTEX para técnicos medios y auxiliares, n. 1).

21. Faschingbauer TR, Devaul RA, Zisook S. Development of the Texas Inventory of Grief. Am J Psychiatry. 1977;134:696-8.

22. Levav I, Kohn R, Montoya I, Palacio C, Rozic $\mathrm{P}$, Salano I, et al. Training Latin American primary care physicians in the WPA module on depression: results of a multicenter trial. Psychol Med. 2005;35(1):35-45.

23. World Health Organization. Composite International Diagnostic Interview, version 2.1. Geneva: WHO; 1997.

24. Horowitz M, Wilner N, Alvarez W. Impact of Event Scale: a measure of subjective stress. Psychosom Med. 1979; 41:209-18.

25. Shah BV, Barnwell BG, Bieler GS. SUDAAN user's manual. Release 7.5. Research Triangle Park: Research Triangle Institute; 1997.

26. Sabin M, Lopes Cardozo B, Nackerud L, Kaiser R, Varese L. Factors associated with poor mental health among Guatemalan refugees living in Mexico 20 years after civil conflict. JAMA. 2003;290:635-42.

27. Kohn R, Levav I. Bereavement in disaster: an overview of the research. Int J Ment Health. 1990;19:61-76.

Manuscript received 24 August 2004. Accepted for publication 14 June 2005 
RESUMEN Objetivos. En América Latina no se han estudiado suficientemente los trastornos por estrés postraumático (TSP) y otras afecciones piscopatológicas mediante muestras basadas en la comunidad. El presente estudio explora varias reacciones psicopatoló-

Reacciones psicológicas y psicopatológicas en Honduras después del huracán Mitch: implicaciones para la planificación de los servicios gicas y sus respectivos factores de riesgo dos meses después de que el huracán Mitch azotó Honduras en octubre de 1998.

Métodos. En Tegucigalpa, capital de Honduras, se seleccionó a 800 personas de 15 años de edad o más que vivían en áreas residenciales consideradas de estatus socioeconómico alto, medio o bajo y que habían sufrido los devastadores efectos del huracán en mayor o en menor medida. Para diagnosticar los casos de TSP se utilizó la Entrevista Diagnóstica Internacional Compuesta. La depresión, el abuso de alcohol y la reacción de dolor se evaluaron mediante encuestas de tamizaje, mientras que para la desmoralización se empleó el Cuestionario de Síntomas. Se aplicó la Escala de Impacto de Eventos para establecer la gravedad de la reacción postraumática.

Resultados. Se encontró TSP en 10,6\% de la muestra. Los encuestados de las áreas residenciales más afectadas estaban más angustiados, tuvieron una mayor puntuación en la evaluación de sufrimiento, y presentaron síntomas de TSP de mayor gravedad. También presentaron mayores tasas de prevalencia de depresión mayor, alcoholismo y problemas emocionales previos. El mejor modelo explicativo del riesgo de sufrir TSP tomó en cuenta el grado de exposición según los eventos traumáticos informados y el incremento de la desmoralización asociada con ellos. Entre las personas con TSP, los factores pronóstico de la gravedad de los trastornos fueron el pertenecer al sexo femenino y el grado de exposición a los eventos traumáticos relacionados con el huracán.

Conclusiones. Se calcula que del total de 3,3 millones de adultos (de 15 años de edad o más) habitantes de Honduras, más de 492000 han sufrido TSP debido al huracán Mitch. Para contar con una adecuada preparación sanitaria y ofrecer una apropiada respuesta ante los desastres es necesario reconocer en profundidad los múltiples efectos psicológicos que experimentan las víctimas.

Palabras clave Desastres, salud mental, trastornos mentales, trastornos por estrés postraumático, Honduras.

A veces no nos dan a escoger entre las lágrimas y la risa, sino sólo entre las lágrimas, y entonces hay que saberse decidir por las más hermosas.

Maurice Maeterlinck, autor belga (1862-1949) 